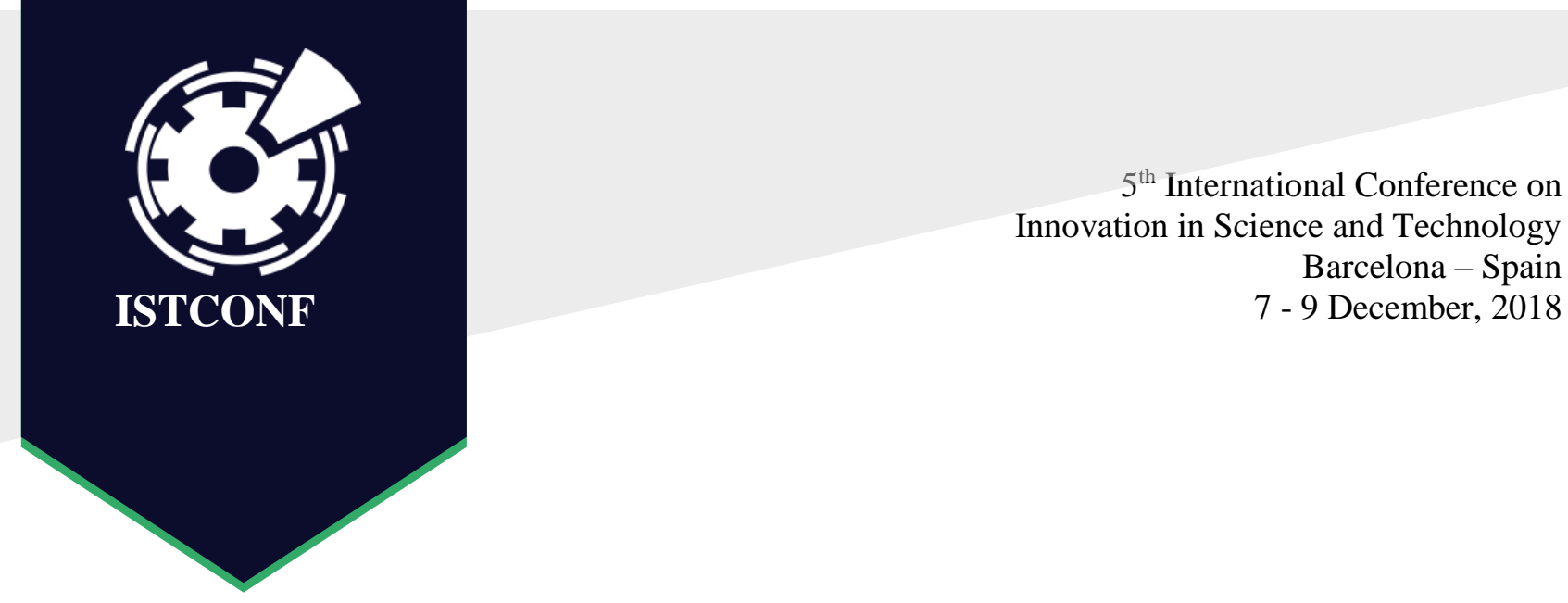

\title{
Torque and Speed Control of BLDC Motor for Pedelec
}

\author{
O. UYAR, M. CUNKAS
}

\author{
Dept. of Electric \& Electronic Engineering, Selcuk University
}

\begin{abstract}
This paper presents the mathematical model control of a pedelec. This model includes the vehicle and the electric motor dynamics. Brushless Direct Current (BLDC) motor on the pedelec provide contribution to the pedal axle in the bottom bracket through the motor connection axle connect with the worm gear. Human torque contribution on the pedal crank has a shape of cosine function. Thus the control system mimic this human torque and track the desired velocity. Cascade PI control blocks have been used for controlling the torque and speed value. Torque shape of the motor should mimic the human torque and cruise control objective has been achieved with $0.017 \mathrm{~m} / \mathrm{s}$ error as mean value.
\end{abstract}

\section{Introduction}

Every day, the population of the world is migrating from rural areas to city centers. This leads to large cities with very large population densities. All developed and developing countries will be affected by these developments. Larger cities create a need for new transport and infrastructure, which means new market dynamics for companies in many sectors. New technologies, products and engineering solutions are created to solve the original problems arising from this urbanization scale.

One of the massive problems of the large cities is transportation. The rate of people preferring individual transportation increases with the higher standard of life and speed of work rhythm. Thus, most of the people use vehicles lonely to go to work or entertainment. In today's conditions, lots of facilities and manufacturers are required to meet the green technology feature to provide energy conservation, carbon reduction and environmental protection policies. In line with this demand, the automotive sector has begun to show interest in electrification of vehicles. Therefore, Light Electric Vehicles (LEVs) and Electric Bikes (EPACs) draw great interest. Electric bicycles with light weight, less pollution and noise are becoming a popular green means of transport.

As well as other two-wheeled vehicles, electrically power assisted bicycles also known as Pedelec has attracted great interest. Unlike the commonly sold electric bicycle, pedelec give chance to the users getting the pleasure of driving of bicycle and physical exercise. Moreover, lowerpowered electric motor and less battery requirement are the main advantages of the pedelecs. Because of all these distinctions, there is a growing up attention in the literature for pedelecs and ebikes.

The studies related to Pedelec and EPACS focus on battery management systems, performance comparisons of motor types, speed and torque control methods, metabolic and environmental effects of using these vehicles as personalized transportation. Chang-Hua Lin et all. present a charge system that includes bi-directional buck-boost power converter for driving motor and re-use the energy resulted from the motor to charge battery [1]. Another work relevant to battery is a smart boost converter for using battery/supercapacitor combination. They collect extra current from the super capacitor module and provide an improvement in the uphill acceleration of the bicycle as well as preventing deep discharge of the battery [2]. Effect of the motor types such as inner-outer rotor permanent magnet and different geared BLDC motors are also examined [3, 4]. Healt effects of cycling is evaluated with different parameters such as electromyography signals, cardiorespiratory 


\section{$5^{\text {th }}$ International Conference on \\ Innovation in Science and Technology \\ Barcelona - Spain \\ 7 - 9 December, 2018}

ISTCONF

gensumption, rate of perceived exertion, enjoyment and they have compared these parameters of non-assisted cycling [5]. The effect of the dynamic parameters such as mass winel speed, wheel diameter are determined besides the modelbased control of the system is implemented for tracking the desired speed [6].

Most of the works are related to the control methods of the EPACs. Artificial intelligence found a place in this working area. Gear positions of a bicycle have been adjusted with the help of Fuzzy Logic. The system takes the riding speed, pedaling rate, pedaling torque and make a decision for changing the gear ratio [7]. In another fuzzy application, the system perceives the current speed and the gear position and adjusts the pulse width modulation (PWM) signal to control the speed of bicycle in downhill-uphill environment [8]. Disturbance observer is a frequently used method in speed control applications that has external disturbance such as gravitational force and frictional force [9, 10]. These observers are also used for the estimation of the pedaling torque of the rider without using the torque sensor $[11,12]$.

Human behavior is a vague parameter in simulation works. In pedelec modeling it is important how can the model mimics the rider's intelligence. Researchers have used various approaches. PingHo Chen has been modeled the human as a PID controller whose output is mechanical pedal torque [13]. Similarly, the rider have been interpreted with $P$ and I coefficients in order to simulate the response time of the rider to track the desired velocity and controller reply the demand with torque [14]. Human torque has been considered as a cosine function proportional to the maximum human torque besides the desired and measured velocity parameters [15].

This paper presents a numerical representation and a simulation work for our pedelec design. The environmental impact on the electrically assisted bicycle is interpreted by means of this dynamic model. Human torque is modeled as cosine function. Control system is designed to mimic the human torque and track the desired velocity. So we used cascade PI control blocks for controlling the torque signal like cosine function and catch the reference speed value.

The continuation of the article is arranged as follows: in section II the pedelec description is presented. Section III with three subtitles includes the mathematical representation of the whole system. Simulink design about this system is described in section IV and finally, model simulation results are illustrated in section $\mathrm{V}$.

\section{Pedelec Description}

The preliminary study of our pedelec design with an innovative center hub mechanism is shown in Fig.1. The mechanism includes components such as worm gear, module gear, one-way bearing, modified pedal axle and gearbox. 
$5^{\text {th }}$ International Conference on Innovation in Science and Technology

Barcelona - Spain

\section{ISTCONF}

Figure 1: Preliminary Design of Our Pedelec

The BLDC motor provides power assistance to the pedal axis in the middle hub with the help of the worm gear. Worm gear rotates the module gear; the pedal shaft is rotated through the instrument of the one-way bearing which is coincident with the module gear. The unidirectional bearing also allows the pedal to be turned independently of these mentioned gears. Such electric assisted bicycles reduce the energy expenditure of the rider. Although we have mentioned this design to clarify the study, the dynamic simulation and control of this system is the main focus point. 
$5^{\text {th }}$ International Conference on Innovation in Science and Technology

Barcelona - Spain

\section{ISTCONF}

\subsection{Bicyere longitudinal dynamics}

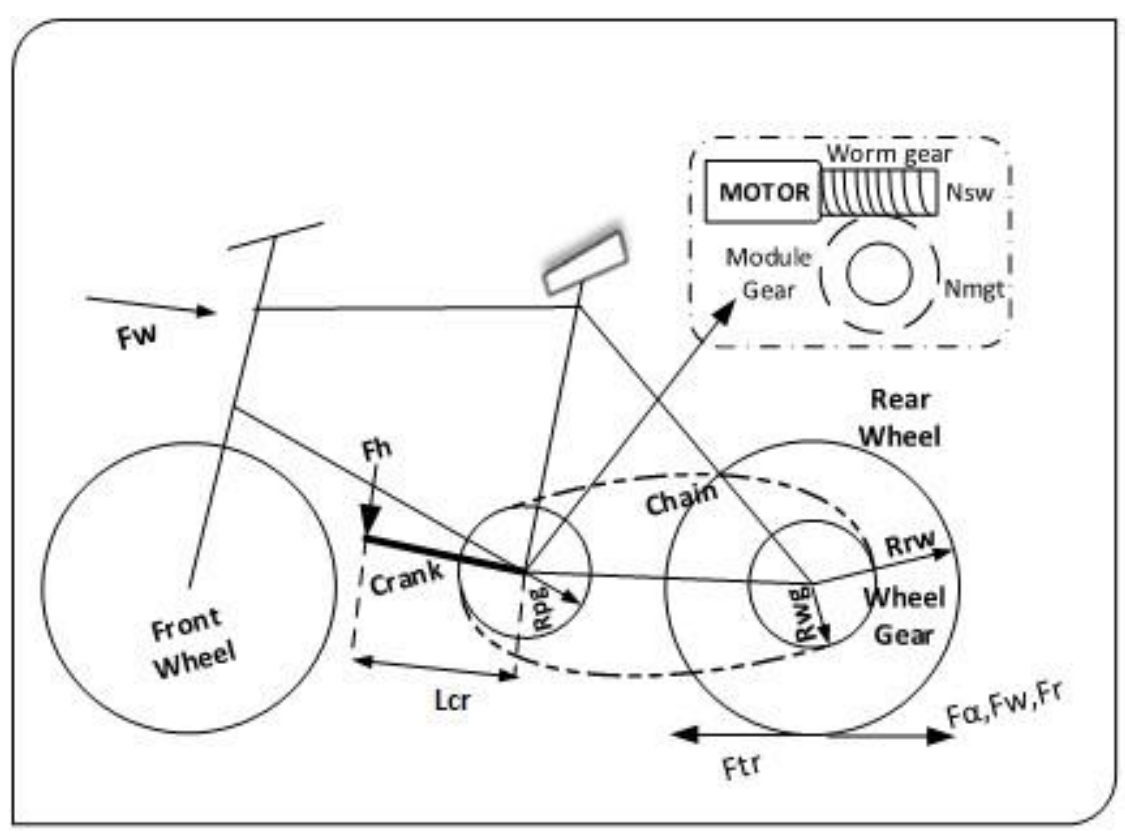

Figure 2: Force Descriptions of Pedelec

Pedelec motion is depicted in Fig. 2 that includes commonly used resistance forces assumed that affecting only rear wheel. It is formulated as,

$$
F_{t r}-F_{\alpha}-F_{r}-F_{w}=m_{T} \cdot \frac{d V}{d t}
$$

where $\mathrm{V}$ is the longitudinal velocity of pedelec wheel, $\mathrm{t}$ is the time, $\mathrm{F}_{\alpha}$ is gradient resistance force, $\mathrm{F}_{\mathrm{r}}$ is rolling resistance, $\mathrm{Fw}$ is wind resistance. All of these components had mentioned in our previous work [16].

Control of the system is related to the motor so it would be better to transfer the forces to the motor shaft. Therefore gear ratios and their efficiencies are required as follows:

$$
\begin{array}{cc}
n_{1}=\frac{N_{m g t}}{N_{w s}}=\frac{40}{2} ; & \eta_{1}=0,85 \\
n_{2}=\frac{R_{w g}}{R_{p g}=1 ;} & \eta_{2}=0,96
\end{array}
$$


$5^{\text {th }}$ International Conference on Innovation in Science and Technology

Barcelona - Spain

\section{ISTCONF}

where $\mathrm{n}_{1}$ is worm gear - module gear ratio, $\mathrm{n}_{2}$ is wheel gear - pedal gear ratio, $\mathrm{N}_{\mathrm{mgt}}$ is module gear tooth count, $\mathrm{N}_{\mathrm{ws}}$ is start count of worm gear, $\mathrm{R}_{\mathrm{wg}}$ and $\mathrm{R}_{\mathrm{pg}}$ are whell gear and pedal gear, respectively, $\eta_{1}$ and $\eta_{2}$ are efficiency values of transformation.

\subsection{Motor dynamics}

Brushless DC motor fed by voltage source inverter should be considered with three groups of equations. First one is the stator voltage equations related to the phase components of star connected the motor are in (4) - (6).

$$
\begin{aligned}
& V_{a}=R i_{a}+L \frac{d i_{a}}{d t}+E_{a} \\
& V_{b}=R i_{b}+L \frac{d i_{b}}{d t}+E_{b} \\
& V_{c}=R i_{c}+L \frac{d i_{c}}{d t}+E_{c}
\end{aligned}
$$

where $\mathrm{R}$ is resistance, $\mathrm{L}$ is inductance of each phase, $\mathrm{i}_{\mathrm{a}, \mathrm{b}, \mathrm{c}}$ is the phase current and $\mathrm{E}_{\mathrm{a}, \mathrm{b}, \mathrm{c}}$ is the back emf values. Simulation environment related to the inverter section is constituted as shown in Fig. 3 and the pole to phase conversion is carried out with the Matlab function as shown in Fig.4.

The second equation group is back emf values and they can be calculated as follows:

$$
E_{x}=K_{e} f_{x}\left(\theta_{e}\right) w_{m}, x=a, b, c
$$

where $\mathrm{K}_{\mathrm{e}}$ is the back-emf constant, $\mathrm{w}_{\mathrm{m}}$ is mechanical rotor speed and the $\mathrm{f}_{\mathrm{x}}$ is the trapezoidal function which forms the $\mathrm{K}_{\mathrm{e}} \cdot \mathrm{W}_{\mathrm{m}}$ value as trapezoidal shape according to the electrical rotor angle $\left(\theta_{\mathrm{e}}\right)$. 
$5^{\text {th }}$ International Conference on Innovation in Science and Technology

Barcelona - Spain

\section{ISTCONF}

The other equation is about electromagnetic torque.

$$
T_{m}=\left(E_{a} i_{a}+E_{b} i_{b}+E_{c} i_{c}\right) / w_{m}
$$

The equation of the motion system with inertia $\mathrm{J}_{\mathrm{m}}$, friction coefficient $\mathrm{B}_{\mathrm{m}}$, and load torque $\mathrm{T}_{\mathrm{L}}$ is given as:

$$
\frac{d w_{m}}{d t}=\frac{T_{m}-T_{L}-B_{m} w_{m}}{J_{m}}
$$

The damping coefficient $\mathrm{B}_{\mathrm{m}}$ is generally small and often neglected. The mechanical rotor speed and position are related as:

$$
\frac{d \theta_{m}}{d t}=w_{m}
$$

The general equation for defining system in state space is as follows:

$$
\begin{aligned}
& x(t)=A x(t)+B u \\
& y(t)=C x(t)+D u
\end{aligned}
$$

where :

$$
\begin{gathered}
x=\left[\begin{array}{ccc}
i_{a} i_{b} & i_{c} & w_{m} \\
\theta_{m}
\end{array}\right]^{T} \\
u=\left[V_{a}-E_{a} V_{b}-E_{b} V_{c}-E_{c} T_{e}-D\right]^{T}
\end{gathered}
$$

where :

$$
D=\frac{m_{T} g \sin \alpha(t) R_{r w}}{n_{2} \eta_{2} n_{1} \eta_{1}}+\frac{f_{c r} m_{T} g R_{r w}}{n_{2} \eta_{2} n_{1} \eta_{1}}+\frac{C_{w} A R_{r w}{ }^{3} \gamma_{a} w_{m}{ }^{2}}{2 n_{2}{ }^{3} \eta_{2} n_{1}{ }^{3} \eta_{1}}
$$

Motor parameters can be shown in Table 2:

Table 1: BLDC Motor Parameters

\begin{tabular}{|l|l|}
\hline $\mathrm{Ke}(\mathrm{V} / \mathrm{rpm})$ & 0.0285 \\
\hline $\mathrm{Kt}(\mathrm{Nm} / \mathrm{A})$ & 0.033 \\
\hline Pole & 8 \\
\hline $\mathrm{La}(\mathrm{H})$ & $0.15 \mathrm{e}-3$ \\
\hline $\mathrm{Ra}(\Omega)$ & 0.06 \\
\hline Power $(\mathrm{W})$ & 600 \\
\hline Speed $(\mathrm{rpm})$ & 3000 \\
\hline Torque $(\mathrm{Nm})$ & 2 \\
\hline
\end{tabular}


$5^{\text {th }}$ International Conference on Innovation in Science and Technology

Barcelona - Spain

ISTCONF

7 - 9 December, 2018

\section{nironment}

The ystem model has different parts such as human torque representation, BLDC motor and inverter model and other mechanical relations. Human force that is applied on the pedal crank are taken to be only in the vertical direction. Since there are two cranks $180^{\circ}$ out of phase from one another when one crank is not being pushed the other one provide the force. Therefore, equation 13 should

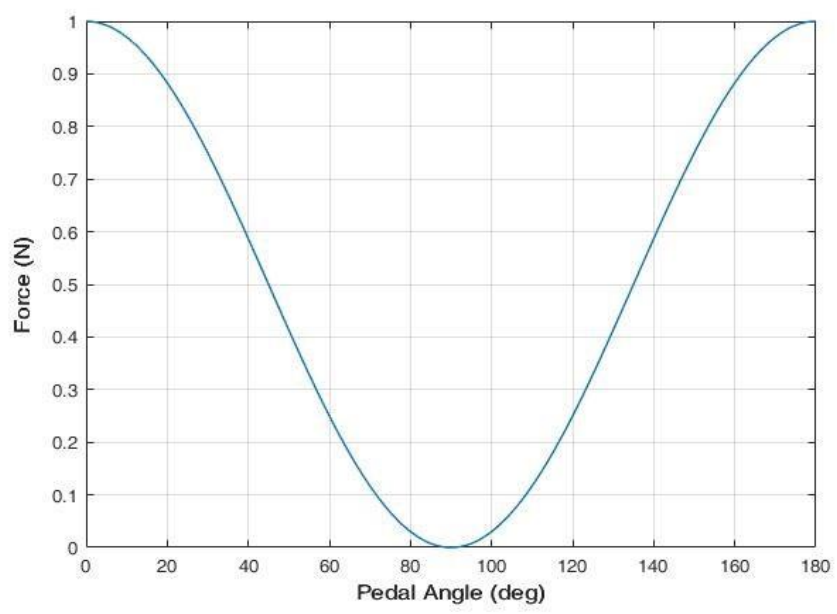

Figure 5: Pedal Force Representation

be used for determining the current force value connected with the crank angle. So the force value is maximum when the angle is $0^{\circ}$ and perpendicular force is maximum when the angle is $90^{\circ}$. The result of this equation is shown in Fig.5.

$$
F_{C}=\frac{1}{2}\left(\cos 2 \theta_{c}+1\right) F r
$$

Whole model has been presented in Fig.6. As shown in Part A of Fig. 6 the inputs of this module get back-emf signals, load torque and phase voltages produced by inverter, outputs are angular velocity, electrical angle and mechanical torque. The Part B in Fig.6 includes a voltage source inverter which use the electrical angle and angular velocity values and produce phase voltages and back-emf values. 
$5^{\text {th }}$ International Conference on Innovation in Science and Technology

Barcelona - Spain

ISTCONF

7 - 9 December, 2018

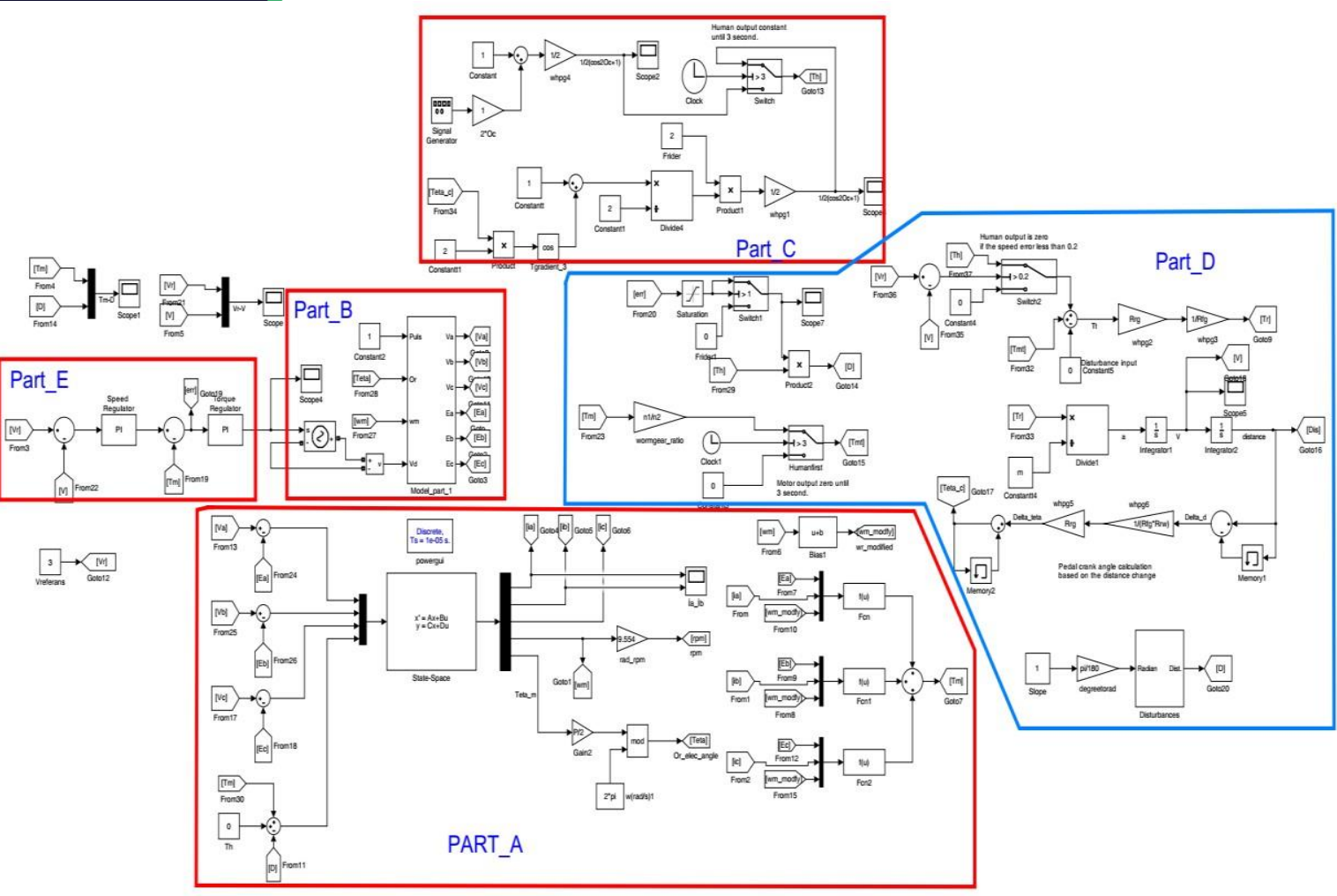

Figure 6: Simulink Model

Human forces on the pedal cranck is modeled in Part C. Mechanical conversions, speed and pedal angle calculations are constructed in Part D. Cascaded PI controller can be shown in Part E. Parameters of speed controller are 150 and 0.2 for $\mathrm{P}$ and I, respectively.

\section{Simulation Results}

The simulation has been run for 50 seconds. We choose the fixed step size $1 \mathrm{e}-5$ and the solver was ode3 (Bogacki-Shampine). Powergui block has been used with discrete simulation type, Tustin solver and $1 \mathrm{e}-5$ as step size.

The desired speed has been taken as $3.5 \mathrm{~m} / \mathrm{s}(12.6 \mathrm{~km} / \mathrm{h})$ and gradient resistance has been neglected. Other disturbances take into account.

Fig. 7 shows the pedelec velocity with the reference value that is $3.5 \mathrm{~m} / \mathrm{s}$. Though the environment disturbances change by time, motor and human-driven torque provide keeping up the reference value with $0.017 \mathrm{~m} / \mathrm{s}$ error as mean value. The human torque and motor torque can be shown in Fig. 8. We can see that required torque for overcoming disturbances and acceleration has been provided by both rider and motor. 
$5^{\text {th }}$ International Conference on Innovation in Science and Technology

Barcelona - Spain

\section{ISTCONF}

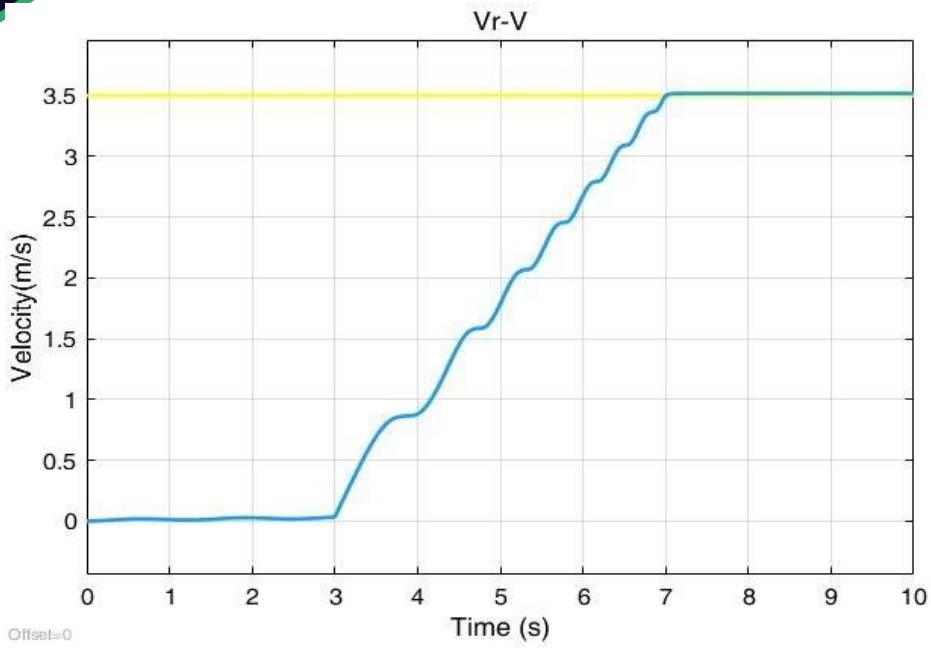

Figure 7: Velocity Response of the Controller
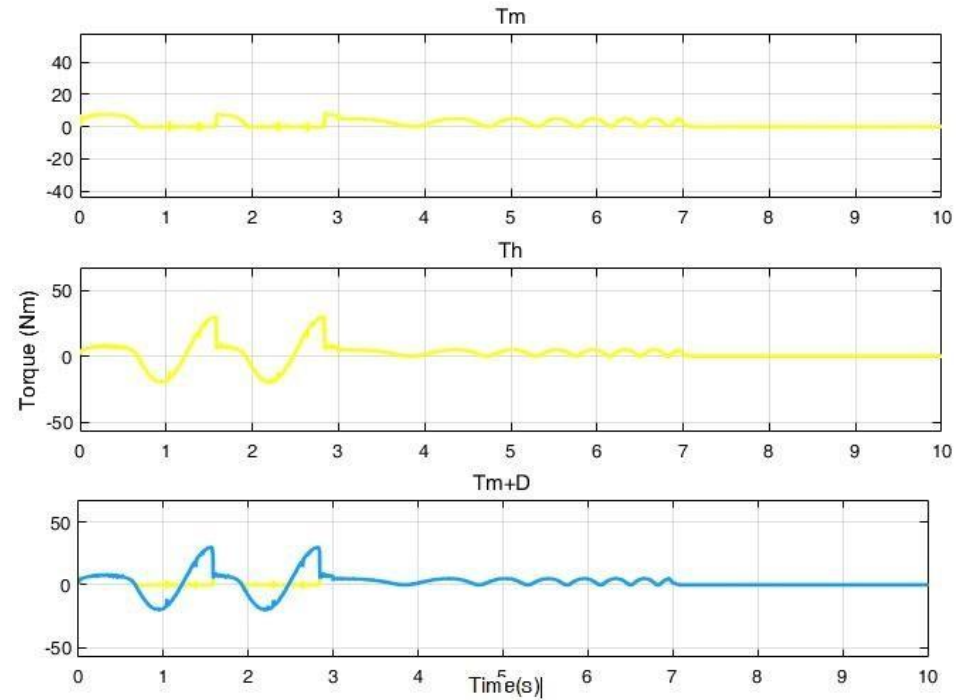

Figure 8: Motor-Human Torque

\section{Conclusion}

Pedelec has interaction with the rider and motor so human contribution has to be modeled. In this study the rider provides the required torque in a cosine form. This structure should be modified for more realistic modeling which considers the motor and human input values are in relationship.

In this study, BLDC motor has been modeled in state space form. The system characteristics can be evaluated for different machine and environment parameters which can be easily varied in the simulation study thanks to the flexible structure of this model. PI control has been used for testing the model. While the cruise control has been achieved with $0.017 \mathrm{~m} / \mathrm{s}$ error as mean value, there is not interaction between the human torque contribution and the motor torque. Torque control is achieved only for imitate the human torque shape with regard to the pedal angle that is calculated from vehicle speed. For further studies, acceleration control should be done in order to ensure comfortable riding and the human-motor interaction should be done for more realistic simulation. 
$5^{\text {th }}$ International Conference on Innovation in Science and Technology

Barcelona - Spain

\section{ISTCONF}

port of this work was provided by Scientific Research Project Coordination Unit of Selcuk University (Project Number: 15101002).

\section{References}

1. Lin, C.-H., H.-W. Liu, and C.-M. Wang. Design and implementation of a bi-directional power converter for electric bike with charging feature. in Industrial Electronics and Applications (ICIEA), 2010 the 5th IEEE Conference on. 2010. IEEE.

2. Manoj, E., D. Isa, and R. Arelhi, Supercapacitor/battery hybrid powered electric bicycle via a smart boost converter. World Electric Vehicle Journal, 2010. 4(2): p. 280-286.

3. Chlebosz, W., G. Ombach, and J. Junak. Comparison of permanent magnet brushless motor with outer and inner rotor used in e-bike. in Electrical Machines (ICEM), 2010 XIX International Conference on. 2010. IEEE.

4. Starschich, E. and A. Muetze. Comparison of the performances of different geared brushless-DC motor drives for electric bicycles. in Electric Machines \& Drives Conference, 2007. IEMDC'07. IEEE International. 2007. IEEE.

5. Sperlich, B., et al., Biomechanical, cardiorespiratory, metabolic and perceived responses to electrically assisted cycling. European journal of applied physiology, 2012. 112(12): p. 4015-4025.

6. Hung, N.B., S. Jaewon, and O. Lim, A study of the effects of input parameters on the dynamics and required power of an electric bicycle. Applied Energy, 2017. 204: p. 1347-1362.

7. Lin, T. Apply fuzzy logic to smart-bike controller design. in Uncertainty Modeling and Analysis, 2003. ISUMA 2003. Fourth International Symposium on. 2003. IEEE.

8. Liang, C.-Y., W.-H. Lin, and B. Chang. Applying fuzzy logic control to an electric bicycle. in Innovative Computing, Information and Control, 2006. ICICIC'06. First International Conference on. 2006. IEEE.

9. Chang, S.-B., et al., Velocity control with disturbance observer for pedal-assisted electric bikes. Vehicle system dynamics, 2012. 50(11): p. 1631-1651.

10. Fan, X. and M. Tomizuka. Robust disturbance observer design for a power-assist electric bicycle. in American Control Conference (ACC), 2010. 2010. IEEE.

11. Sankaranarayanan, V. and S. Ravichandran. Torque sensorless control of a human-electric hybrid bicycle. in Industrial Instrumentation and Control (ICIC), 2015 International Conference on. 2015. IEEE.

12. Cheon, D. and K. Nam, Pedaling torque sensor-less power assist control of an electric bike via modelbased impedance control. International journal of automotive technology, 2017. 18(2): p. 327-333.

13. Chen, P.-H. Application of fuzzy intelligence to Elebike control design. in Fuzzy Systems, 1997., Proceedings of the Sixth IEEE International Conference on. 1997. IEEE.

14. Cardone, M., S. Strano, and M. Terzo, Optimal power-assistance system for a new pedelec model. Proceedings of the Institution of Mechanical Engineers, Part C: Journal of Mechanical Engineering Science, 2016. 230(17): p. 3012-3025.

15. Chen, P.-C., et al. The torque control of human power assisted electric bikes. in System Science and Engineering (ICSSE), 2010 International Conference on. 2010. IEEE.

16. UYAR O., CUNKAS M. State Space Modelling and Simulation For Pedelec. in 6th International Conference on Advanced Technology \& Sciences (ICAT'Riga). 2017. Riga, Latvia. 